\title{
Comparative pollination role of stamens and breeding system in three species of Commelina (Commelinaceae) in Ile-Ife, Nigeria
}

\author{
Matthew Oziegbe $^{1,2}$, Isaiah Opeyemi Akinlua ${ }^{1}$ and Adebiyi Abdul-hakeem Olalekan ${ }^{1}$
}

Received: 11 October, 2012. Accepted: 31 May, 2013

\begin{abstract}
This study investigated pollination mechanisms and breeding systems in five Commelina variants: two subspecies of Commelina diffusa (C. diffusa subsp. aquatica and C. diffusa subsp. montana, each having two staminodes); two variants of C. erecta (with three staminodes); and C. lagosensis (also with three staminodes). In all three species, the staminodes have six lobes but only two fertile lateral lobes. We collected field samples and cultivated new plants from stem cuttings. When the plants flowered, we evaluated floral morphology, floral biology and breeding systems, creating eight separate experimental treatments, involving spontaneous and hand pollination, as well as varying degrees of emasculation of the flowers. Although the pollen from the lateral and central anthers was capable of siring seeds, the staminode pollen rarely set seeds. Commelina diffusa subsp. aquatica presented very low percent pollen stainability in all three of its stamens and produced no seeds in any of the pollination treatments. In all three species, the stigma was often directed toward the central anther during coiling of the style. Our results show that $C$. diffusa subsp. aquatica is sterile and that, in the other Commelina variants studied, pollination occurs mainly through autogamy via the lateral and central anthers.
\end{abstract}

Key words: Commelina, pollen viability, stamen type, autogamy

\section{Introduction}

The two outstanding features of Commelinaceae flowers that affect their reproductive biology are their lack of nectar and their brief flowering times (generally a few hours, always less than a day). Their flowers are usually brightly colored. The parts of the androecium that specifically may attract potential pollen vectors are anthers, filament hairs, pollen, and anther or pollen-like structures-staminodes and hairs (Faden 1992a).

A common feature in the Commelinaceae is anther dimorphism, which indicates the division of labor between stamens modified for pollinator attraction and those producing pollen for pollination (Vogel 1978; Faden 1992a). Walker-Larson and Harder (2000) list pollinator attraction through visual cues or by providing floral rewards, a role commonly filled by staminodes. The visually prominent staminodes in Commelina coelestis Willd. may serve to mimic large quantities of pollen and draw the attention of visiting insects to the center of the flower, away from the cryptically colored lateral anthers that would then deposit pollen to be vectored to the stigmas of neighboring flowers on the abdomen of insects (Vogel 1978).
Despite the general knowledge of and interest in the various stamen types in Commelina flowers, relatively little information is available on the androecium structure in the genus. The production of two or more types of stamens in the same flower (heteranthery) may help reduce the fitness costs arising from pollen consumption by pollinators by allowing different sets of stamens to specialize in "pollinating" and "feeding" functions. The loss of pollen may be significant for plants with nectarless flowers, in which pollen usually represents the only floral reward for animal pollinators, known as buzz-pollinated species (Buchmann 1983). This situation can have important evolutionary consequences when the offer of pollen as food to attract pollinators (i.e., in exchange for pollination) lowers the total number of gametes available for crossfertilization and reduces fitness. Investigation of potential adaptive solutions for reconciling these contrasting pollen fates in nectarless flowers has received relatively little attention in the literature on floral function and evolution (Harder 1990; Harder \& Wilson 1997; Luo et al. 2008). In the present study, we investigate the pollination roles of the three stamen types (staminodes, central stamen and lateral stamens) and the breeding system of Commelina

\footnotetext{
${ }^{1}$ Obafemi Awolowo University, Department of Botany, Ile-Ife, Nigeria
}

2 Author for correspondence: oziegbem@oauife.edu.ng 
erecta Linn., Commelina diffusa Burm.f. and Commelina lagosensis C.B.Cl.

\section{Materials and methods}

\section{Studied species}

We investigated three Commelina species represented by five variants: one variant of $C$. lagosensis; two variants of C. erecta (C. erecta $\mathrm{e}_{1}$, with deep blue petals, and C. erecta $\mathrm{e}_{2}$, with light blue petals) and two C. diffusa subspecies (C. diffusa subsp. aquatica Morton and C. diffusa subsp. montana Morton). Commelina lagosensis has been recorded from Senegal to Southern Nigeria, and also occurring in East Africa. Three subspecies of C. erecta are widespread in West Africa and have also been reported from tropical Africa, the eastern United States, Argentina, and Puerto Rico. Commelina diffusa, which is also widely distributed in many countries of West Africa, has been reported from the southeastern United States. Commelina species mostly occur in wet, disturbed soils, although some species can exist in drier environments (Burkill 1985).

The experiment was carried out in the Department of Botany of Obafemi Awolowo University, in the city of Ile-Ife, Nigeria. The stems of the following Commelina species were collected at various sites within the borders of the Obafemi Awolowo University campus, listed here as geographic coordinates (elevation): C. erecta $\mathrm{e}_{1}$ and C. erecta $\mathrm{e}_{2}$ at $07^{\circ} 31.146^{\prime} \mathrm{N} ; 004^{\circ} 31.583^{\prime} \mathrm{E}(287 \mathrm{~m})$ and $07^{\circ} 31.146^{\prime} \mathrm{N}$, $004^{\circ} 31.583^{\prime} \mathrm{E}(287 \mathrm{~m}) ;$ C. lagosensis at $07^{\circ} 31.151^{\prime} \mathrm{N}$; $004^{\circ} 31.545^{\prime} \mathrm{E}(290 \mathrm{~m})$ and $07^{\circ} 31.148^{\prime} \mathrm{N}$; 004 $31.571^{\prime} \mathrm{E}$ $(288 \mathrm{~m})$; and C. diffusa subsp. aquatica at $07^{\circ} 31.082^{\prime} \mathrm{N}$; $004^{\circ} 31.531^{\prime} \mathrm{E}(277 \mathrm{~m})$ and $07^{\circ} 31.592^{\prime} \mathrm{N}$; 004 ${ }^{\circ} 31.869^{\prime} \mathrm{E}(271$ $\mathrm{m})$. We collected C. diffusa subsp. montana along Olonade Street in Ile-Ife, at $07^{\circ} 30.372^{\prime} \mathrm{N}$; 004³2.373'E (901 m) and $07^{\circ} 30.305^{\prime} \mathrm{N}$; $004^{\circ} 32.801^{\prime} \mathrm{E}(284 \mathrm{~m})$. We planted stem cuttings of in $36 \mathrm{~cm}$-diameter plastic buckets, using five replicates per sample. Plants were allowed to flower before data collection began. For each variant collected, voucher specimens were deposited in the Herbarium of the Botany Department of Obafemi Awolowo University, in Ile-Ife (code, IFE).

\section{Floral morphology}

The numbers of male and hermaphrodite flowers per spathe were determined by observing the type of flower that bloomed each day in 20 selected spathes of each variant. Thirty flowers were randomly collected from each accession. Petals were removed, and the lengths of the central filament, lateral filament and staminodes filament were measured using vernier calipers. Filament length was recorded as the distance between the pedicel-receptacle junction and the anther-filament junction (Ushimaru \& Nakata 2002); style length was determined in a similar manner, from the pedi- cel-receptacle junction to the stigma. Colors of the various anther types were determined before anther dehiscence. Photomicrographs of staminode anthers were documented with a digital camera (MT, version 3.0.0.1; Amscope, Irvine, CA, USA) coupled to a light microscope (XSZ-107BN; Jiangsu Zhengji Instruments Co., Jintan, China).

\section{Floral biology}

Pollen viability was determined from 20 flowers of each variant by staining pollen grains extracted from two anthers of each anther type with cotton blue in lactophenol for approximately $48 \mathrm{~h}$ for each collection. Full pollen grains in which the cytoplasm content stained uniformly blue were counted as viable, whereas those that did not stain or were partially stained and with collapsed outline were counted as non-viable (Olorode \& Baquar 1976). In each of the accessions, the time of opening and closing of flowers, anther dehiscence and insect visitation were observed three times a week between $0400 \mathrm{~h}$ and $1300 \mathrm{~h}$ over a period of four months.

\section{Breeding system}

The numbers of viable ovules per ovary were counted in 10 ovaries in order to evaluate the seed-set. Ten flowers of each variant/accession were used for each of eight pollination treatments. In the first five treatments, the flowers were either not manipulated or were selectively emasculated and bagged to test spontaneous self-pollination:

a) complete emasculation

b) no emasculation

c) only lateral stamens remaining

d) only central stamen remaining

e) only staminodes remaining

In the last three treatments, the flowers were completely emasculated before pollination and the stigma was hand pollinated by touching it with pollen from an anther of only one of the three stamen types, stamens from the same flower being used as the pollen source:

a) pollination with a lateral stamen

b) pollination with the central stamen

c) pollination with staminodes

In all eight experimental conditions, the flowers were bagged after each pollination treatment, in order to prevent exposure to foreign pollen. Seeds were collected from successful treatments prior to fruit dehiscence, and the seed-set was calculated for each of the treatments.

Statistical analysis was performed using the SAS system, version 9.2 (SAS Institute, Cary, NC, USA). The measurements obtained were subjected to one-way ANOVA, and means were compared using Duncan's multiple range test. 


\section{Results}

\section{Floral morphology}

All three of the Commelina species studied are andromonoecious. Commelina erecta variants produced a maximum of six hermaphrodite flowers and three staminate flowers per spathe, although some spathes did not produce staminate flowers. Commelina lagosensis produced a maximum of five hermaphrodite flowers and two staminate flowers per spathe. Commelina diffusa variants produced maximum of five hermaphrodite flowers and one staminate flower per spathe. Commelina erecta $\mathrm{e}_{1}$ and C. diffusa subsp. aquatica produced deep blue petals, whereas $C$. erecta $\mathrm{e}_{2}$, C. lagosensis and C. diffusa subsp. montana produced light blue petals (Fig. 1-5). The C. erecta variants and C. lagosensis showed yellow in their lateral and central anthers, whereas the $C$. diffusa subspecies showed brown in their lateral anthers but yellow in the central anther. Commelina erecta variants and C. diffusa subspecies showed yellow in their staminodes, whereas C. lagosensis staminodes were light yellow (Fig. 1-5).

Commelina erecta and C. lagosensis both produced six stamens, whereas the $C$. diffusa subspecies produced only five (Fig. 1-5). In both C. erecta variants and in C. lagosensis, the stamens were arranged in such a way that the lateral anthers were in close proximity to the stigma, closer than was the central anther (Fig. 6 and 7). Apart from the arrangement of the stamens in the flowers, another factor that seemed to determine the proximity of the lateral anther to the stigma was filament length. In C. erecta and C. lagosensis, the filaments of the lateral stamens were nearly as long as the style and were longer than the filament of the central stamen, whereas the filaments of the staminodes were much shorter than were the other filaments (Fig. 6 and 7, Tab. 1). The central anther was closest to the stigma in C. diffusa. All three Commelina species showed staminodes with six lobes. Of those six lobes, the two upper and two lower lobes were sterile, whereas the central lobes contained small amounts of pollen (Fig. 12-14).

\section{Floral biology}

The percent pollen stainability of the three anther types of each species is shown in Tab. 2. Percent pollen stainability was very low in all of the stamen types of Commelina diffusa subsp. aquatica $(6.10-17.40 \%)$. In all of the species studied, percent pollen stainability was significantly lower for

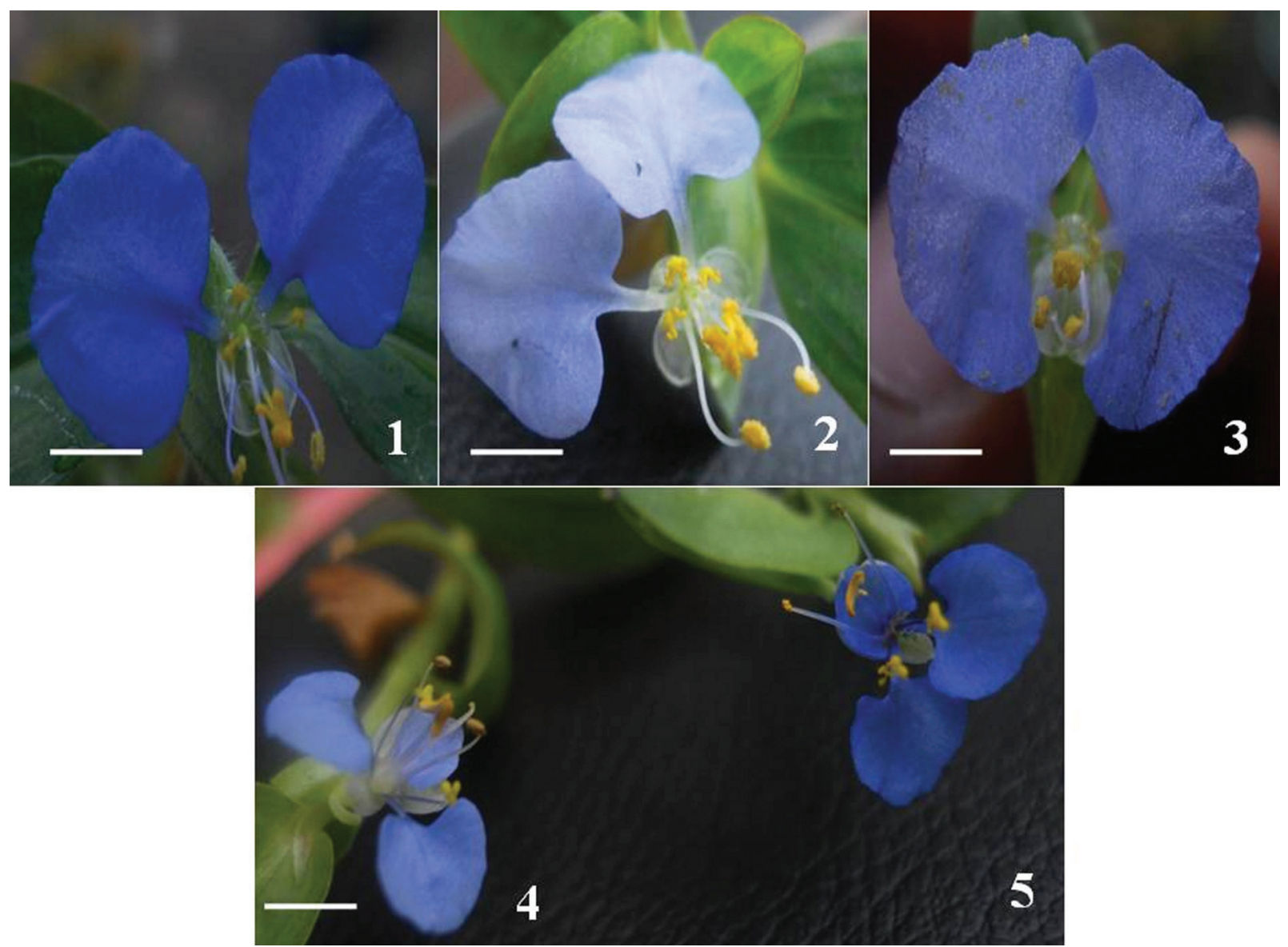

Figures 1-5. Floral morphology of the studied Commelina species and variants. 1. C. erecta Linn. e. 2. C. erecta Linn. e. 3. C. lagosensis C.B.Cl. 4. C. diffusa subsp. montana Morton 5. C. diffusa subsp. aquatica Morton. Bars $=6 \mathrm{~mm}$. 

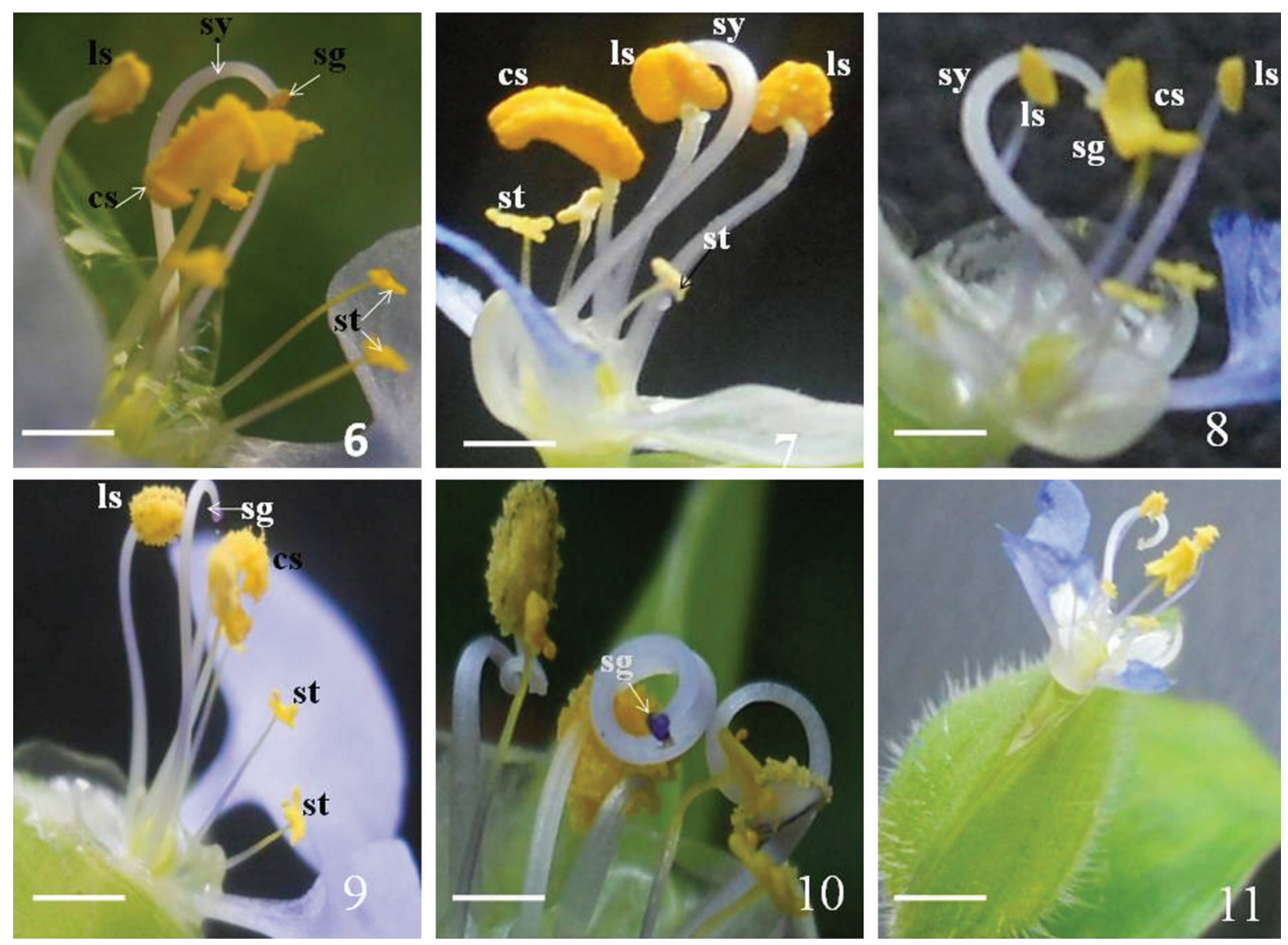

Figures 6-11. Coiling of the style in the studied Commelina species. 6. Pollinated stigma hitting the lateral anther in C. erecta Linn. 7. Stigma hitting the lateral anther in C. lagosensis C.B.Cl. 8. and 9. Stigma directed towards the central anther in C. lagosensis C.B.Cl. and C. erecta Linn. 10. Curled style with non-pollinated stigma, having missed all the anthers in C. diffusa Morton. 11. Style in the early stages of curling with stigma already missing the anthers in C. lagosensis C.B.Cl. Bars $=2 \mathrm{~mm}$.

ls - lateral anther; cs - central anther; st - staminode; sy - style; sg - stigma.

Table 1. Comparative mean lengths of filaments and style (cm) within each Commelina accession.*

\begin{tabular}{lccccc}
\hline \multirow{2}{*}{ Structure } & \multicolumn{2}{c}{ Commelina erecta Linn. } & Commelina lagosensis & \multicolumn{2}{c}{ Commelina diffusa } \\
& variant $\mathrm{e}_{1}$ & variant $\mathrm{e}_{2}$ & C.B.Cl. & subsp. aquatica Morton & subsp. montana Morton \\
\hline Lateral stamen & $0.77 \pm 0.14 \mathrm{~b}$ & $0.87 \pm 0.16 \mathrm{a}$ & $0.55 \pm 0.07 \mathrm{~b}$ & $0.50 \pm 0.06 \mathrm{a}$ & $0.59 \pm 0.06 \mathrm{a}$ \\
Central stamen & $0.63 \pm 0.05 \mathrm{c}$ & $0.58 \pm 0.09 \mathrm{~b}$ & $0.46 \pm 0.04 \mathrm{c}$ & $0.43 \pm 0.03 \mathrm{~b}$ & $0.48 \pm 0.03 \mathrm{~b}$ \\
Staminode & $0.52 \pm 0.04 \mathrm{~d}$ & $0.52 \pm 0.05 \mathrm{c}$ & $0.30 \pm 0.03 \mathrm{~d}$ & $0.34 \pm 0.04 \mathrm{c}$ & $0.36 \pm 0.05 \mathrm{c}$ \\
Style & $0.91 \pm 0.01 \mathrm{a}$ & $0.85 \pm 0.01 \mathrm{a}$ & $0.70 \pm 0.01 \mathrm{a}$ & $0.52 \pm 0.01 \mathrm{a}$ & $0.45 \pm 0.01 \mathrm{~b}$ \\
\hline
\end{tabular}

${ }^{*}$ Results shown as mean \pm standard error; means followed by same letter in the same column indicate that there was no significant difference ( $\left.p>0.05\right)$ between the two.
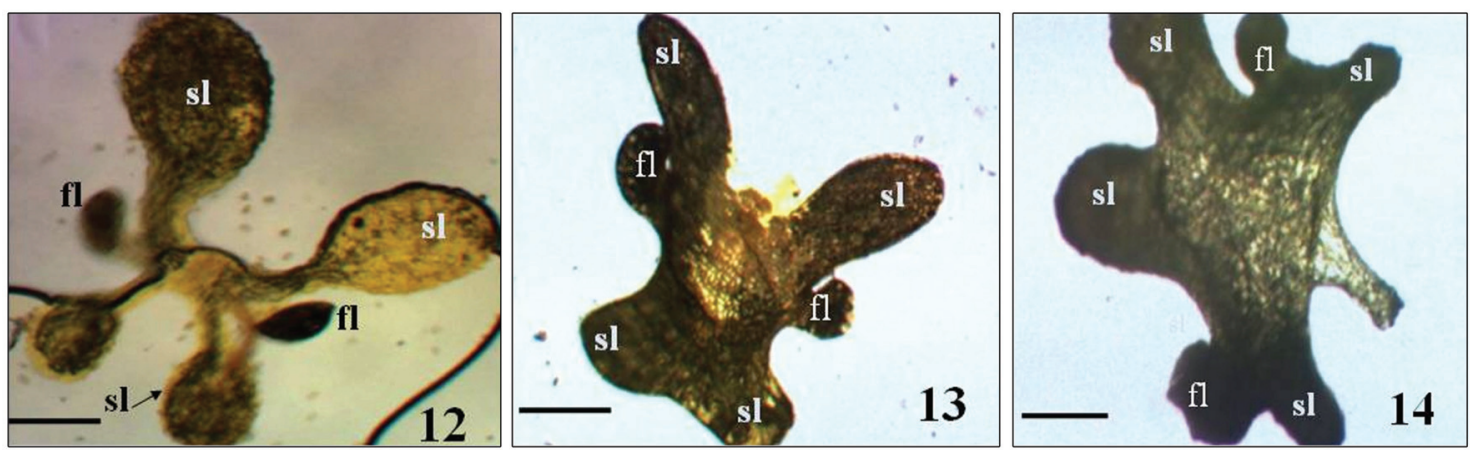

Figures 12-14. Structure of staminode anther showing two fertile lateral lobes and the four sterile lobes in the three Commelina species. 12. C. diffusa Morton. 13. C. erecta Linn. 14. C. lagosensis C.B.Cl. Bars $=2 \mathrm{~mm}$.

sl - sterile lobe; fl - fertile lobe. 
Table 2. Percent pollen stainability of each stamen type in each Commelina accession.*

\begin{tabular}{lccccc}
\hline \multirow{2}{*}{ Structure } & \multicolumn{2}{c}{ Commelina erecta Linn. } & Commelina & \multicolumn{2}{c}{ Commelina diffusa } \\
& variant $\mathrm{e}_{1}$ & variant $\mathrm{e}_{2}$ & lagosensis C.B.Cl. & subsp. aquatica Morton & subsp. montana Morton \\
\hline Lateral stamen & $95.50 \pm 1.31 \mathrm{a}$ & $92.00 \pm 1.40 \mathrm{a}$ & $95.50 \pm 1.50 \mathrm{a}$ & $16.70 \pm 2.23 \mathrm{a}$ & $84.90 \pm 1.30 \mathrm{a}$ \\
Central stamen & $97.10 \pm 1.20 \mathrm{a}$ & $86.90 \pm 1.60 \mathrm{~b}$ & $87.30 \pm 1.50 \mathrm{~b}$ & $17.40 \pm 1.40 \mathrm{a}$ & $85.50 \pm 1.22 \mathrm{a}$ \\
Staminode & $49.10 \pm 2.40 \mathrm{~b}$ & $81.60 \pm 1.80 \mathrm{c}$ & $57.70 \pm 2.21 \mathrm{c}$ & $6.10 \pm 0.48 \mathrm{~b}$ & $75.00 \pm 1.62 \mathrm{~b}$ \\
\hline
\end{tabular}

${ }^{\star}$ Results shown as mean \pm standard error; means followed by same letter in the same column indicate that there was no significant difference ( $\left.\mathrm{p}>0.05\right)$ between the two.

staminode pollen than for central and lateral pollen (Tab. 2). Percent pollen stainability of lateral and central stamens was highest in C. erecta, C. lagosensis and C. diffusa subsp. montana (Tab. 2).

Flowers of Commelina lagosensis opened as early as 0430 $\mathrm{h}$ and began to close as early as $0830 \mathrm{~h}$; anther dehiscence took place between $0530 \mathrm{~h}$ and $0615 \mathrm{~h}$ in the central and lateral anthers but at a later time in the staminodes. In C. diffusa subsp. aquatica and C. diffusa subsp. monta$n a$, flowers opened at approximately $0730 \mathrm{~h}$ and $0800 \mathrm{~h}$, respectively, and started closing at approximately $1100 \mathrm{~h}$. Dehiscence of their central and lateral anthers occurred at 0900-1000 h. The flowers of the C. erecta variants started opening as early as $0500 \mathrm{~h}$ and started closing at approximately $1030 \mathrm{~h}$, dehiscence of their central and lateral anthers occurring at approximately $0630 \mathrm{~h}$. Insects were not observed visiting the flowers of any of the three Commelina species in their habitat.

In all three Commelina species, when the style coiled, it typically directed the stigma towards the central anther. In addition, while coiling, the stigma brushed the lateral anther and became dusted with pollen before hitting the central anther. In some cases, the coiling stigma missed the lateral anther and hit the central anther, thereby taking pollen directly from the central anther. Occasionally, the stigma missed the anthers of all the three stamen types and subsequently coiled in without having taken any pollen, thus remaining unpollinated (Fig. 6-11).

\section{Breeding system}

Commelina erecta and C. lagosensis presented three viable ovules per ovary, whereas the $C$. diffusa subspecies presented five viable ovules per ovary. The average seed-set per fruit and number of fruits produced from each treatment of the five studied variants were recorded (Tab. 3). Regardless of the treatment, C. diffusa subsp. aquatica produced no fruit; nor did the flowers that were completely emasculated in the self-pollination treatments of all three species (Tab. 3). In the spontaneous self-pollination treatment with no emasculation, a high seed-set was observed for all of the variants except $C$. diffusa subsp. aquatica (Tab. 3). The flowers of the C. erecta variants and of $C$. diffusa subsp. montana presented a high percent seed-set from their spontaneously self-pollinated flowers for which only the lateral or central stamens remained, whereas C. lagosensis, although also showing a high seed-set from spontaneously self-pollinated flowers with only the lateral stamens remaining, showed a low seed-set from those with only the central stamen remaining (Tab. 3). The spontaneous self-pollinated treatments of flowers with only the staminode remaining showed a seed-set of $10 \%$ in C. erecta $\mathrm{e}_{1}$ and no fruit production in the other variants (Tab. 3). In the hand pollination treatments, C. erecta variants, C. lagosensis and C. diffusa subsp. montana presented relatively high seed-set from their lateral and central stamens, higher than the spontaneous self-pollinations with corresponding stamens for C. erecta variants and C. lagosensis (Tab. 3). Hand self-pollinations with staminode stamen produced fruits only in C. diffusa subsp. montana (Tab. 3).

\section{Discussion}

Andromonoecy (hermaphrodite and staminate flowers on the same plant), as observed in the Commelina species studied here, has been reported to be common in the genus (Mc Collum et al. 1984; Faden 1985, 2000). However, the Commelina variants studied produced more hermaphrodite flowers than staminate flowers. Kaul \& Koul (2008) reported a similar observation regarding Commelina caroliniana Walter.

The blue color of the petals, as well as the bright yellow color of the lateral and central anthers, of the three species of Commelina studied here indicates their ability to attract insects, as suggested for the central stamen of C. erecta (Faden 1992b). However, we observed no insects foraging on the anthers of any of the studied species. They contrast with the flowers of C. caroliniana and Commelina benghalensis L., which are brightly colored and are visited by numerous insects, mainly hymenopterans (Kaul \& Koul 2008; 2012). The light yellow color of the staminode in C. lagosensis is not attractive so it might not play the role of insect attraction known for staminodes in other Commelina species.

Among the stamens of the three studied species of Commelina, the staminodes were found to be the shortest and the lateral stamens the longest. Hrycan \& Davis (2005) reported that, in C. coelestis and Commelina dianthifolia Delile, the staminode stamen is intermediate in size between the lateral and central stamen. The authors suggested that the anther 
Table 3. Average number of seeds per fruit, number of fruits produced and seed-set from pollination treatments on each accession of Commelina.

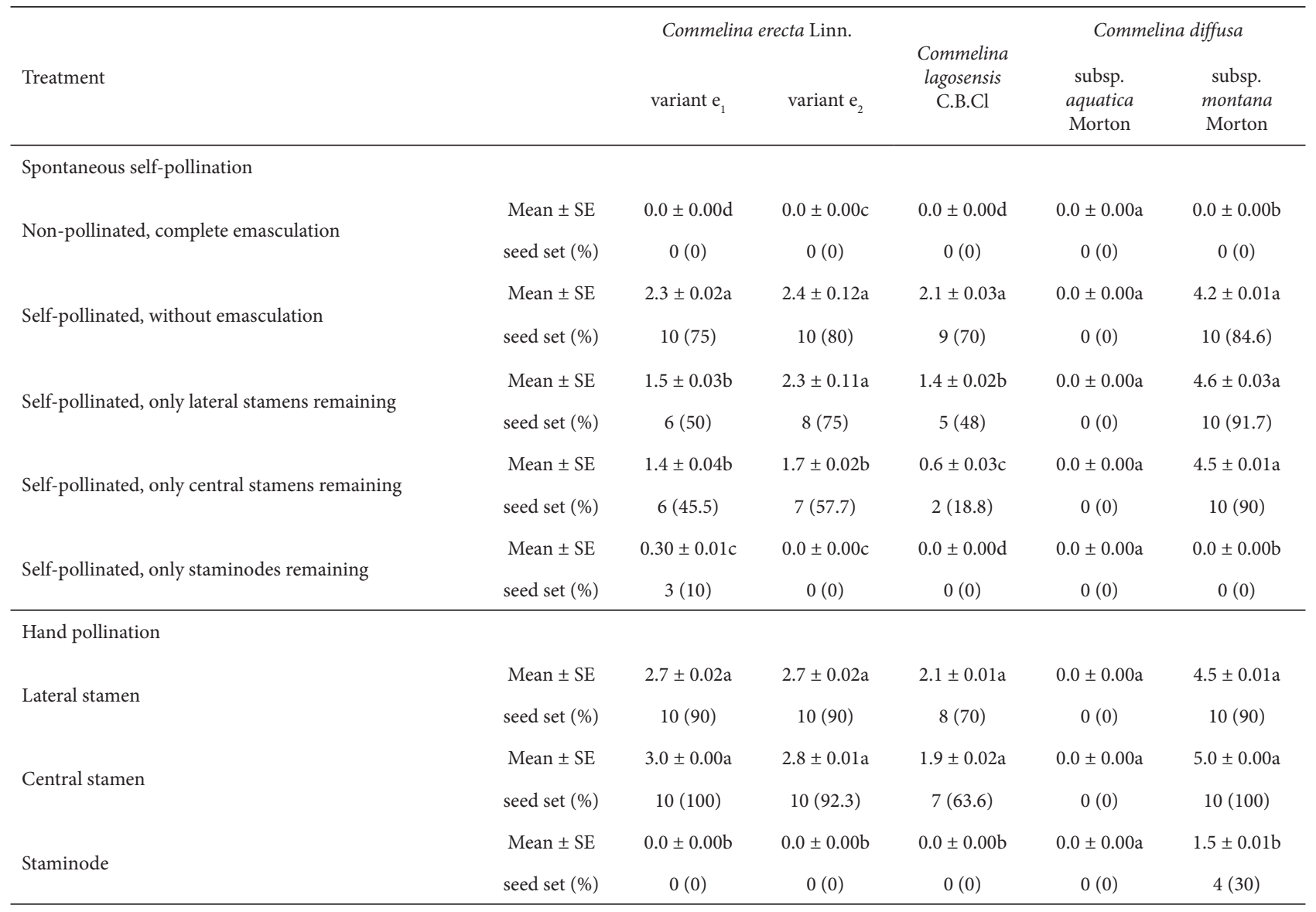

${ }^{*}$ Means followed by same letter in the same column indicate that there was no significant difference $(\mathrm{p}>0.05)$ between the two.

and pistil arrangement in Commelina implies that the genus is entomophilous. Nevertheless, the coiling behavior of the style observed in the present study suggests autogamy and members of the Commelinaceae have previously been reported to be self-compatible (Faden 1992b), as reported here. The styles of hermaphrodite, chasmogamous flowers of C. benghalensis, Commelina forskalaei Vahl. and C. dianthifolia also coil, brushing the stigma against the fertile central stamen (Maheshwari \& Maheshwari 1955; Hrycan \& Davis 2005). The flowers of $C$. caroliniana are suggested to be structured for cross-pollination, but autonomous selfing occurs when cross-pollination fails (Kaul \& Koul 2008), which is a good explanation for the findings of our study.

Our results indicate that, in Commelina erecta variants, C. lagosensis and C. diffusa subsp. montana, the lateral and central stamens are both quite effective at autogamy. In flowers exhibiting autogamy, the stigma and anther are typically in close proximity (Ushimaru \& Nakata 2002). In C. coelestis and C. dianthifolia, Hrycan \& Davis (2005) observed that the stigma is close to the lateral anther, although the authors found that the central stamen is responsible for autogamy in the latter species. In all three of the species studied here, the stigma did not take pollen from the sta- minodes. We also observed that the stigma often missed the stamens entirely and took no pollen during coiling. These events might be responsible for the relatively small number of fruits observed in the spathes, in relation to the number of flower buds. In all three species, the stigma coils in first, after which the three different anther types wilt, the petals wilting and folding thereafter. Petal wilting prior to style coiling towards the central stamen, as reported in C. coelestis, creates a barrier that prevents the stigma from coming into contact with the central stamen (Hrycan \& Davis 2005), a phenomenon that was not observed in the present study.

The high percent pollen stainability of the central and lateral stamens in Commelina erecta, C. lagosensis and C. diffusa subsp. montana showed that the pollen grains are capable of siring seeds. This is reflected in the high seed-set from their lateral and central stamens in the spontaneous and hand pollination treatments. However, the percent pollen stainability was significantly higher in the lateral stamen than in the central stamen of C. erecta $\mathrm{e}_{2}$ and C. lagosensis. This resulted in a significantly higher seed-set from the lateral stamen than from the central stamen in the self-pollination treatments, indicating that the lateral stamen will contribute more to seed production than will the 
central stamen in these species. Mc Collum et al. (1984) called the central anther of C. erecta a feeding anther and proposed it to be analogous to nectar, serving only to provide a reward for pollinators and having very little to do with fertilization. In the present study, a significantly higher seed-set was observed in hand pollination treatments than in spontaneous self-pollination treatments using lateral and central stamens, which indicates that pollen from these stamens does not always get to the stigma or that the pollen load on the stigma is reduced during self-pollination. Kaul \& Koul (2008) made a similar observation regarding C. caroliniana. Although we observed a high percent pollen stainability (49-81\%) in the staminodes of C. erecta, C. lagosensis and C. diffusa subsp. montana, the low seed-set from staminodes in spontaneous and hand pollination indicated that the staminodes do not play a direct role in the pollination of these species, as observed in other species (Kaul \& Koul 2012). This might be explained by the small quantity of pollen, the shorter filaments of the staminodes and the inability of its fertile lobes to dehisce (Hrcyan \& Davies 2005; Kaul \& Koul 2008; Kaul \& Koul 2012). Although staminodes have been shown to have nutritive and attractive functions (Ronse \& Smets 2001), Hrycan \& Davis (2005) reported that the role of staminodes is unclear in Commelina species. Staminodes that produce pollen rewards are generally sterile (Yeo 1993), which is not exactly the case observed in the present study, in which the percent pollen stainability was high in all variants except $C$. diffusa subsp. aquatica. Nevertheless, Faden (2000) reported that anthers responsible for pollinator attraction alone may contain less reward than do pollinating anthers.

The inability of Commelina diffusa subsp. aquatica flowers to set fruits and seeds in all of the treatments was due to the very low percent pollen stainability and possibly to the non-viability of its three types of stamen. Commelina diffusa subsp. aquatica is quite similar to C. diffusa var. gigas, as described by Faden (1993), who observed that the latter rarely sets seeds, although occasionally producing one or two seeds per capsule. The percent pollen stainability of $6.10-17.40 \%$, in C. diffusa subsp. aquatica is much lower than the 53-78\% stainability reported for C. diffusa var. gigas (Faden 1993). Faden (1993) also speculated that sterility occurs due to the hexaploid nature of $C$. diffusa var. gigas. Nearly half of all Commelina species are polyploid, and members of the genus are known to show irregular multiples of the basic number of chromosomes (Grabiele et al. 2005). Although polyploidy occurs in C. diffusa, most variants of the species (70\%) are diploid (Grabiele et al. 2005). However, the subspecies of $C$. diffusa investigated here have been reported to have a diploid chromosome number of $2 \mathrm{n}=30$ (Umoh et al. 1991a), whereas C. erecta variants are predominantly polyploid (Grabiele et al. 2005), and the two C. erecta variants investigated here have been reported to be tetraploid- $2 \mathrm{n}=4 \mathrm{x}=60$ (Umoh et al. 1991b).
In the three Commelina species studied here, pollination is mainly through autogamy and insects were not observed foraging on the anthers of any of the species. Pollen from the central and lateral anthers are capable of siring seeds spontaneously, except in C. diffusa subsp. aquatica, which shows low pollen stainability. There is need for meiotic chromosome studies in C. diffusa subsp. aquatica, in order to identify the factors responsible for its low pollen stainability. Although staminodes showed medium to high percent pollen stainability, they set fruits in low proportions and are not considered efficient in spontaneous self-pollination.

\section{References}

Buchmann, S.L. 1983. Buzz pollination in angiosperms. Handbook of Experimental Pollination Biology. Pp. 73-113. In: Jones, C.E. \& Little, R.J. (Eds.). New York, Scientific and Academic Editions.

Burkill, H.M. 1985. The useful plants of West Tropical Africa. V. 1. Pp 426-435.

Faden, R.B. 1985. Commelinaceae. Pp. 381-387. In: Dahlgren, R.M.T.; Clifford, H.T. \& Yeo, P.F. (Eds.). The families of the monocotyledons: structure, evolution, and taxonomy. Berlin, Springer-Verlag.

Faden, R.B.1992a. Proposal to conserve Commelina benghalensis (Commelinaceae) with conserved type under Art. Taxon 41: 341-342.

Faden, R.B. 1992b. Floral attraction and floral hairs in the Commelinaceae. Annals of the Missouri Botanical Garden 79: 46-52.

Faden, R.B. 1993. The misconstrued rare species of Commelina (Commelinaceae) in the Eastern united states. Annals of the Missouri Botanical Garden 80: 208-218.

Faden, R.B. 2000. Floral biology of Commelinaceae. Pp.309-317. In: Wilson, K.L. \& Morrison, D.A. (Eds.). Monocots, systematic and evolution. Melbourne, CSIRO Publishing.

Grabiele, M.; Davina, J.R. \& Honfi, A.I. 2005. Chromosomes of four species of Commelina (Commelinaceae). Botanical Journal of the Linnean Society 148: 207-218.

Harder, L.D. 1990. Behavioural responses by bumble bees to variation in pollen availability. Oecologia 85: 41-47.

Harder, L.D. \& Wilson, W.G. 1997. Theoretical perspectives on pollination. Acta Horticulture 437: 83-101.

Hrycan, W.C. \& Davis A.R. 2005. Comparative structure and pollen production of the stamens and pollinator-deceptive staminodes of Commelina coelestis and C. dianthifolia (Commelinaceae). Annals of Botany 95: 1113-1130.

Kaul, V. \& Koul A.K. 2008. Floral phenology in relation to pollination and reproductive output in Commelina caroliniana (Commelinaceae). Australian Journal of Botany 56: 59-66.

Kaul, V. \& Koul A.K. 2012. Staminal varation and its possible significance in Commelina benghalensis L. and Commelina caroliniana Walter. Current Science 105: 419-426.

Luo, Z.; Zhang, D. \& Renner, S.S. 2008. Why two kinds of stamens in buzz-pollinated flowers? Experimental support for Darwin's divisionof-labour hypothesis. Functional Ecology 22: 794-800.

Maheshwari, P. \& Maheshwari, J.K. 1955. Floral dimorphism in Commelina forskalaei Vahl. and C. benghalenis L. Phytomorphology 5: 413-422.

McCollum, T.M.; Estes, J.R. \& Sullivan J.R. 1984. Reproductive biology of Commelina erecta (Commelinaceae). Pp. 57-66. In: Horner N.V. (Ed.). Festschrift for Walter W. Dalquist in honour of his sixty-sixth birthday. Wichita Falls: Midwestern State University, Department of Biology.

Olorode, O. \& Baquar, S.R. 1976. The Hyparrhenia involucrate-H. subplumosa (Gramineae) complex in Nigeria: morphological and cytological characterization. Botanical Journal of the Linnean Society 72: 211-222.

Ronse Decrane, L.P. \& Smets, E.F. 2001. Staminodes: their morphological and evolutionary significance. The Botanical Review 67: 351-402. 
Umoh, E.O.; Hossain, G.M. \& Ene-Obong, E.E. 1991a. On interchange complexes in Commelina diffusa Burn F. from South eastern Nigeria. Cytologia 56: 173-179.

Umoh, E.O.; Hossain, G.M. \& Ene-Obong, E.E. 1991b. Cytogenetics of Commmelina erecta Linn. from South eastern Nigeria. Cytologia 56: 181-186.

Ushimaru A. \& Nakata K. 2002. The evolution of flower allometry in selfing species. Evolutionary Ecology Research 4: 1217-1227.
Vogel, S. 1978. Evolutionary shifts from reward to deception in pollen flowers. Pp. 89-96. In: Richards, A.J. (Ed.). The Pollination of Flowers by Insects.

Walker-Larson, J. \& Harder, L.D. 2000. The Evolution of Staminodes in Angiosperms: Patterns of Stamen Reduction, Loss, and Functional Re-Invention. American Journal of Botany 87: 1367-1384.

Yeo, P.F. 1993. Secondary pollen presentation. Form, function, and evolution. New York, Springer-Verlag. 